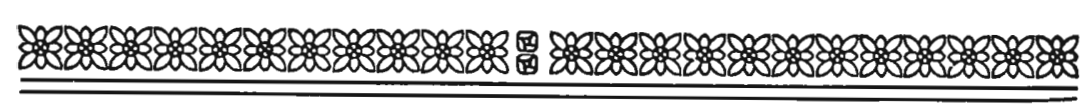

\title{
Democracia e acção social do Estado
}

\begin{abstract}
Discurso proferido a 7 de setembro de 1931, na sessão solenne de collação de gráo á centesima turma de bachareis em sciencias juridicas e sociaes, pelo paranympho professor dr. Vicente Ráo.
\end{abstract}

Iniciando o seu discurso, o professor Vicente Ráo dirigiu especial saudação ao exmo. snr. dr. Laudo de Camargo, m. d. Interventor Federal neste Estado, dizendo-lhe o quanto se sentiam honrados, professores e alumnos da Faculdade de Direito de S. Paulo, com a visita de s. exa.

O exmo. snr. dr. Laudo de Camargo, accrescentou, por suas peregrinas virtudes e por seus altos dotes intellectuaes, é um dos filhos mais illustres desta Faculdade, pois, quer na Judicatura, quer na direcção dos destinos do Estado, sempre tem sabido ser o mesmo cultor, mestre e sacerdote do Direito e da Justiça.

A presença de s. exa., assim terminou o orador sua saudação, era motivo de justo orgulho para a inteira assistencia. 
Cinco annos de convivio nos estudos e em lutas civicas, que a historia ha de accrescentar ao patrimonio já secular e glorioso desta Academia, fizeram-nos amigos.

Esse sentimento de amizade, elle só, eu bem sei, ditou a escolha de vosso paranympho. De mim, que é que se podia esperar nesta solennidade? Uma oração excepcional, reveladora de dotes que não tenho, ou uma palavra singela, vinda do coração do mestre que tanto honrastes, em resposta á voz do vosso coração, numa festa de despedida e, pois, de saudade? Por esta e não por aquella esperança eu justifiquei vossa escolha.

Justifiquei-a, sentindo, ao della ter noticia, um orgulho immenso. Neste instante, porém, ao vêr partir, mundo afóra, armados cavalleiros do direito, os meus primeiros discipulos, a primeira turma perante a qual leccionei nesta $\mathrm{Fa}$ culdade, não sei esconder, confesso, a commoção que me perturba. Não concebe, minha mente, espetaculo mais impressionante, nem outro igual, capaz de revelar, tão ao vivo, o quanto já avancei na vida e o vulto das responsabilidades que já carrego.

Sem duvida, o contacto diario comvosco alimentava ainda de illusões este meu ultimo resto de mocidade; mas, agora, a realidade se impõe, invencivel, ao meu espirito, e delle varre para sempre os sonhos e anseios de outróra.

Dura é a realidade; porém, não a maldigo - porque, resultando, como resulta, de um convivio moral e intellectual, nossa amizade vale pela communhão de nossos ideaes, vale, isto é, pela certeza de seu successo, pois, para realisal-os, ahi está, em esplendida parada, prompta e armada para a lucta, essa pleiade de combatentes, de valor, energia, enthusiasmo e espirito de sacrificio integralmente moços e tantas e tantas vezes comprovados.

Falo em combatentes. Falo em luta. Qual a batalha que está por se ferir? Por mim já respondeu á pergunta vosso talentoso orador: - preciso é, é indeclinavel repôr 
nossa patria no caminho normal que a conduzirá á consecução de seus destinos.

A desorganização material, que campea, pede meças á anarchia mental, que a todos avilta.

Esta mais do que aquella apavora.

A ordem material e juridica facilmente se impõe ou restabelece, quando uma directriz moral inflexivel guia os conductores das massas; mas, quando estes, dispersos, desorientados, sem rumo certo, só se conduzem pelo léo do vento, então, senhores, as perpectivas apparecem sombrias e desoladoras.

Falta-nos a bandeira, embora não nos falte a força, affirmou vosso orador.

Assim não penso eu. Tendes a força de um ideal alevantado, que tambem é a bandeira que vos levará á victoria. Tendes o privilegio da mocidade nesta hora historica de reconstrucção do mundo. A tarefa compete a vós e não ás gerações passadas, porque estas são incapazes de destruir o arcabouço social egoista que ellas proprias ergueram, em quanto que vós, novos e generosos, podeis cavar sem peias os alicerces da nova construcção.

A directriz? A mesma que vos guiou durante o curso academico; a mesma que em sete de Agosto de 1930 vos fez viver um lindo e inolvidavel episodio de coragem civica; a mesma que, em dias recentes, vos consagrou como os unicos bravos capazes de transformar heroicamente, se preciso fôr, as perspectivas sombrias e desoladoras de hoje, no ceu aberto e feliz de amanhã.

Nenhuma duvida tolda o meu espirito sobre o quanto podeis e haveis de fazer. A bella oração, ainda agora proferida, é padrão e segurança de vossa vida futura. Por ella já revelaes um conhecimento preciso sobre a origem do mal que nos afflige. Esse mal não é só nosso, mas de todos os povos civilisados; e se, entre nós, agora assume proporções agudas, é porque nos achamos, neste instante, entre as ruinas de um regimen destruido pela propria podridão e o dever premente de dar estructura e fórma á nova vida politica do 
paiz, antes que o germen da anarchia, por proliferar livremente mais tempo ainda, venha a criar chagas afinal incuraveis em nosso organismo collectivo.

O remedio, senhores, está sobretudo na serenidade dos espiritos, na harmonia mental, na analyse fria, imparcial, objectiva, dos factos: - nunca no açodamento em acolher novidades, sediças ou suspeitas, que a boa ou má fé de pregoeiros sustenta, aconselhando-nos a vestir o Brasil em armazem de roupas feitas, á moda de certos manequins armados em outras terras.

\section{VOLTA Á DEMOCRACIA}

O remedio está na volta á Democracia livre das corruptelas e perversões que no regimen decahido a falsearam, posta ao par das necessidades sociaes contemporaneas, vivificada pela fé dos que a servem.

"Nunca houve principio mais debatido, impugnado e até injuriado, escreveu Assis Brasil, que o principio democratico. A melhor indicação de sua virtude está, entretanto, nisto mesmo: - elle tem sobrevivido ao ataque, tem resistido galhardamente á prova. Pensadores e politicos, decepcionados muitas vezes por factos materiaes real ou apparentemente demonstrativos de incapacidade do povo, proclamam-se descrentes da Democracia. Não advertem que taes factos, ainda quando continuados por um largo periodo de crise social, podem ser excepções que se evidenciam como taes desde que a observação se alargue e seja considerada, não um retalho da evolução, mas a evolução inteira, o conjunto do phenomeno humano em vez de méros incidentes mais ou menos ampliados. De facto, tal scepticismo nasce da observação incompleta, como a do medico que descresse da medicina, da cirurgia ou da hygiene, porque alguma dellas não deu resultado em determinado caso, ou mesmo porque foi causa de algum desastre que se não daria no regimen da completa abstenção da sciencia e da arte. Mas, assim como 
o homem que soffre, urgido pela necessidade, recorre de novo á arte de curar quando seus males se aggravam, tambem o estadista, quando assume a responsabilidade dos destinos de um povo, se sente obrigado a pedir inspirações á limpida fonte da soberania popular, sempre que deseja serenamente traçar os delineamentos de instituições livres".

Proclama-se, contra o valor do principio, sua insufficiencia para acudir ás necessidades sociaes de nossos dias. Não ha contestar, diz-se, a fallencia do regimen economico vigente ainda nos paizes accentuadamente capitalistas, fallencia que se assignala, dia a dia, pela crescente desigualdade de classes, com seu inevitavel sequito de injustiças e de lutas, as quaes, avolumando-se, provocarão a derrocada final da civilisação contemporanea, se logo não se lhes oppuzer paradeiro.

Em tal situação, accrescenta-se, irrisoria apparece a igualdade juridica affirmada pelos principios democraticos, tamanhas são as desigualdades de facto que lançam os homens uns contra os outros, em luta fratricida e de exterminio.

Disso tudo, ha politicos, pois, que o affirmam, é culpada a Democracia.

Mas, senhores, um erro grave, gravissimo, vicia o argumento. Procurarei demonstral-o, acenando á

\section{ORIGEM DA DEMOCRACIA}

Ella nasceu, vós o sabeis, como arma do povo contra a tyrannia, como reacção contra os governos despoticos ou arbitrarios.

No conceito de seu pensadores, caracterisou-se, substancialmente, pelo criterio da "intervenção effectiva do povo no estabelecimento das leis e na nomeação dos funccionarios que hão de executal-as e administrar o interesse publico".

Vindo do povo e não mais do poder dos tyrannos, o governo, na Democracia, embora pelo povo não exercido di- 
rectamente, exercer-se deve de accordo com a média da vontade popular - finalidade, esta, para obtenção da qual a grande lei politica da divisão dos poderes surgiu, pois, no dizer de Montesquieu, "afim de que se não possa abusar do poder, de mister se faz que, por disposição natural das coisas, o poder limite o poder".

Então, a liberdade e a igualdade de todos perante a lei, postulados fundamentaes da concepção democratica, representavam, através da garantia dos direitos individuaes, a suprema conquista da humanidade, como fim de uma éra de privilegios de castas e disparidade de situações perante a ordem juridica.

Na phase inicial, como na phase aurea da Democracia, um incisivo caracter individualista predominou. A propria vida social não destoava desse conceito, por estar organisada sobre a base economica da pequena industria, a qual permittia o destaque, em forte relevo, da individualidade humana.

Comprehende-se, pois, como e porque, então, não houvesse, no terreno economico e, conseguintemente, no terreno social, uma luta de classes tão intensa quanto a de nossos dias.

Comtudo, será o individualismo um postulado inherente, substancial, do conceito da democracia? - Eis o que contesto.

A Edade Média, sob as vestes do Estado Paterno, disfarçava o absolutismo; mas, bem mais velho do que a Sé de Braga é o principio politico da actividade social do Estado, parallelo ao da actividade juridica, havida esta, embora, por obrigatoria, e aquella por meramente subsidiaria, a exercerse, isto é, alli onde a ausencia ou a fraqueza das forças individuaes possa acarretar males ou desordens na sociedade.

Reportemos-nos á acenada causa originaria da democracia: a reacção do povo contra os tyrannos. Definitivamente victoriosa esta reacção, através da Revolução Franceza, a embriaguez do successo obliterou o senso dos vencedo- 
res e fez com que, á sombra de certas doutrinas economicas, par a par com o principio fundamental da organisação politica, erguessem o fetichismo do Estado Indifferente, do E'tat Gendarme, do Estado moldado na formula economica do laissez faire, laissez passer.

Vicio do principio democratico ou perversão de sua pratica? Perversão de sua pratica, senhores! Porque dupla missão, dentro da mais pura democracia, ao Estado se reconhece: - a de instituir e manter a ordem, missão juridica, e a de promover o desenvolvimento da sociedade, missão social; a primeira, envolvendo um principio de organisação politica, sobre as bases da liberdade e igualdade de todos perante a lei, da origem popular do poder e de seu exercicio de accôrdo com a média vontade do povo, - a segunda, attinente á actividade da administração publica, envolvendo um principio de ordem social, sobre a base de competir ao Estado o dever de auxiliar os individuos, como membros componentes da sociedade, como partes de um só todo, na realisação de seus destinos materiaes e moraes na vida.

Verdade é, para lamentar, que uma das duas missões, a ultima, não acompanhou o progresso do meio-ambiente economico e social, pois o preconceito do "indifferentismo" cegou juristas, politicos e estadistas; não lhes fez vêr, com o correr dos tempos, como e quanto, aggravando-se as desigualdades de facto, de novo os homens se dividiram em castas, não mais pelo criterio de privilegios legaes, mas pela razão, mais odiosa ainda, da luta para a conquista dos meios de subsistencia, o que é dizer, da propria vida; não lhe faz ver que, mantida inerte a missão social do Estado, veiu, aos poucos, tornar-se de realisação difficil, senão impossivel, a propria manutenção da ordem juridica.

Obra, esta, do "indifferentismo de Estado", impropriamente dito "liberalismo", mas não defeito ou falha da democracia, em si mesma considerada.

Sómente porque, na pratica e em certo momento historico, a administração não desenvolveu, como devia, sua actividade social, havemos de condemnar o principio politico da 
formação democratica dos governos, confundindo a estructura, a organisação, com a inercia social e voluntaria do Estado?!

\section{A ECONOMIA NOVA.}

A phase economica da pequena industria, não ha quem o ignore, logo cedeu seu lugar á da grande industria.

A machina a vapor, de alta pressão, inventada em 1801; a locomotiva, em 1814; o telegrapho electrico, em 1837; a photographia, em 1839; a primeira linha de navegação transatlantica, em 1840; o telephone, em 1887; o automovel, em 1891; a telegraphia sem fios, em 1900; mais recentemente, a navegação aérea com o mais leve e o mais pesado do que o ar; as ondas hertzianas como conductoras de electricidade - emfim, todo esse mundo novo, que dia a dia mais resplandece aos nossos olhos, revolucionou, com a economia, a vida da sociedade, subverteu a ordem material anterior, reclamando um correspondente progresso do Direito Publico e Privado.

Insistentemente eu vos dizia em minhas prelecções: se uma simples operaria, impulsionando um motor, produz um trabalho que antes dez operarios não produziam; se como consequencia dos citados inventos e do progresso das sciencias applicadas, as grandes industrias surgiram e, por sua vez, criaram poderosissimas organisações dominadas pelos reis do capital e da producção; se em certos ramos, os mais importantes, da actividade humana, preciso foi substituir os contractos individuaes pelos contractos collectivos, nos quaes são partes, não os individuos, mas as classes ás quaes pertencem; se as grandes industrias federadas impõem aos consumidores uma especie unica de contracto, ou seja o chamado "contracto-typo" - se tudo isso succede, infantilidade seria o querer-se encontrar lenitivo, ou cura, para os males sociaes contemporaneos, no individualismo absoluto dos fetichistas do "Estado Indifferente", que 
subverteram o principio puro da Democracia, mutilando-o ao applical-o.

Progrediram as sciencias puras, inclusivé as doutrinas juridicas, pois vozes não faltaram, com modalidades varias, extremadas, umas, sensatas, outras, procurando, todas, despertar o Direito Positivo do entorpecimento em que emperrára; progrediram espantosamente as sciencias applicadas, erguendo, sobre as cinzas de uma economia extincta, uma economia nova; - só as leis não progrediram, só ellas deixaram de acompanhar a evolução social.

\section{O CONCEITO SOCIAL DO DIREITO}

Já em 1838, Pellegrino Rossi formulava severas criticas ao Codigo Civil Francez - monumento maximo da concepção individualista - reputando-o em choques com as relações economicas; Vadalá-Papale, em 1831, no seu escripto $O$ Codigo Civil Italiano e a Sciencia e, mais tarde, Cimbali na Nova Phase do Direito Givil, e D'Aguanno na Reforma Integral da Legislação Civil, foram os iniciadores, na Italia, da corrente nova que, a pouco e pouco, veiu formar a moderna doutrina do direito privado social, inseparavelmente unido a um parallelo conceito do Direito $\mathrm{Pu}-$ blico.

Leroy Beaulieu em França ( $O$ Ciodigo Civil e o Direito Novo), Menger na Allemanha ( $O$ Direito Civil $e$ os Pobres), Valverde, na Hespanha, e tantos e tantos outros proseguiram na obra de desenvolvimento dessa doutrina, que muito passou a dever aos autores germanicos, como propulsores, que foram, do estudo systematico do Direito e não mais do estudo analytico das leis. Conheceis, a seguir, os principios fundamentaes da escola historica e da escola positiva, bem como a influencia por elles exercida na obra grandiosa da renovação do Direito.

Pois bem: - dentre toda as correntes e todos os juristas citados, embora varios e divergentes sejam os systemas, 
extremando-se, uns, ao dar papel absorvente e exclusivista ao factor economico, relegando ao abandono os factores moraes, outros, ao dar predominancia ao factor anthropologico, outros, ainda, ao factor historico, - comtudo, uniforme entre elles apparece a repulsa dos principios individualistas.

Qual a razão dessa uniformidade? Eil-a: - a concepção do Direito, em sua origem, em sua essencia, em sua finalidade, como força eminentemente social.

Deve o direito, de facto, ser considerado como força coordenadora e propulsora ao mesmo tempo. Coordenadora, porque institue e mantém a ordem social através da ordem juridica, ou seja, através da regulamentação das acções e das relações humanas; propulsora, porque, acompanhando o progresso das idéas e o das applicações das sciencias e das artes, deve preparar e conservar, para o homem, o caminho que ha de trilhar na realisação de seus destinos na vida.

Ex facto oritur jus - já diziam os romanos e CoNsENTINI, traduzindo essa expressão synthetica por forma a lhe revelar todo o alcance, diz que o Direito nasce da vida social, transforma-se com a vida social e deve adaptar-se á vida social.

Qual é, no entanto, a situação do direito patrio, sob este aspecto? A de um injustificavel e impressionante atraso.

Carios de Carvalho, é verdade, já nos ensinava, ao tratar do problema da codificação civil, que "a questão não é a possibilidade de se arranjar um codigo, na phrase de Teixeira de Freitas, o problema é outro: - o da organisação de um codigo de direito privado social. Consiste em passar da unidade individualista para a unidade social, em realisar a missão social da sciencia do Direito".

Mas a advertencia de Carlos de Carvalho não impediu que até hoje nos regessemos por um Codigo Commercial elaborado em 1850, por um Codigo Penal feito em 1890, pelas Ordenações do Reino de Portugal, em materia civil, até 
1917 e desta data em diante por um codigo que se limitou a consolidar principios e leis esparsas anteriores.

Não chegarei a affirmar com Andrade Figueira (referindo-se ao projecto de Codigo Civil da Camara dos Deputados), que "dos dois mil duzentos e tres artigos do Codigo, dois mil são copia da legislação de tres seculos; apenas duzentos e tres conterão innovações e, dentre estes, cem não convém, porque até são menos liberaes do que as Ordenações".

Direi, porém, com a paciencia do illustre PoNTES DE MIRANDA, que "das aproximadamente 1.929 fontes do Codigo Civil (abstrahindo-se as legislações estrangeiras), ao direito anterior pertencem 479, á doutrina já vigente antes do Codigo Civil $272 e$ ao Esboço de Teixeira de Freitas, 189. Isto quer dizer: em tudo que se alterou, foi o "Esboco" a fonte principal (Esboco, este, que data de 1866); ou, por outras palavras, que nosso Codigo ainda é mixto de direito romano, de direito canonico e de direito portuguez!

Não ha negar, senhores, o atraso é deveras impressionante!

Somos escravos, ainda, do falso preconceito da "autonomia da vontade individual".

Ora, eu vos pergunto, onde está, intangivel, absoluta, sempre intacta, tão estranha autonomia, por exemplo, em certas relações contractuaes? Qual a autonomia, a liberdade de vontade do operario, que, premido pela fome, acceita o contracto que o patrão lhe impõe? Qual a autonomia, qual a liberdade de vontade do infeliz que toma dinheiro a dez por cento ao mez, com o visto da policia, como succede em nosso Estado, para não perecer á mingua de recursos? Mas, senhores, onde está a autonomia, a liberdade de vontade de cada um de nós, quando compramos um bilhete de estrada de ferro ou de transatlantico, quando embarcamos mercadorias, quando seguramos nossa pessoa ou nossos bens, quando expedimos um telegramma, quando assignamos o serviço telephonico, quando compramos um simples automovel a prestações? Porventura, é-nos licito discutir 
as clausulas de qualquer desses contractos? Não se nos exhibe, sempre, em casos taes, um contracto uniforme, não se nos impõe um typo contractual já redigido e "standardisado"? E se tal é a realidade, porque cultivar ainda mythos que os factos, dia a dia, hora a hora, materialmente desmentem?

\section{OS PRINCIPIOS NOVOS}

A Revolução Franceza, ao lado dos principios politicos da liberdade e da igualdade juridica, affirmou esse principio civil da "autonomia da vontade individual".

Os dois primeiros representam conquistas, que seculos de lutas antecederam. Hão de ser mantidos, porque são inherentes á natureza humana. O ultimo falliu, por haver contribuido para as desigualdades sociaes, ou seja, para a inteira absorpção e dominio dos fracos pelos fortes, ou, ainda, em ultima analyse, para o anniquilamento da individualidade.

Não se confundem "individualidade" e "individualismo".

Pelo contrario, os dois conceitos differem e se chocam, e, neste sentido, apropositada é a lição de NrrTr: "o desenvolvimento da "individualidade" acarreta um accrescimo de funcções, seja em numero, seja em densidade; o desenvolvimento do "individualismo" significa apenas a predominancia do sentimento egoista. Ora, o caminho seguido pela civilisação é tal, que, emquanto, por um lado, tende a accrescer a individualidade, inclina-se, por outro, a destruir o individualismo. Em toda a communhão, ou associação, os membros que a compõem adquirem, cada dia, novos deveres para com a familia, para com o Estado e para com a collectividade. A lei, ou seja, a coerção, torna obrigatorios muitos desses deveres. Não sendo absolutamente Iivre, o individuo apparece, pelo contrario, ligado por mil modos, sem poder ser o arbitro absoluto de sua conducta, nem o interprete cego de seus proprios instinctos - por isso, o "indi- 
vidualismo" decresce. Mas sob outro aspecto, justamente porque os laços com a communidade cada vez mais se estreitam, a "individualidade" se desenvolve, cresce. E o homem não só apparece protegido na vida, mas ainda, após muitas evoluções seculares, protegido tambem apparece na sua capacidade de trabalho, na sua integridade moral e em sua propria liberdade - por isso, a "individualidade" prospera. Conseguintemente, licito é affirmar-se que "todo o desenvolvimento da invidualidade outra coisa nâo é senão uma diminuiçẫo do individualismo".

Attentae bem: - combatendo o individualismo, não preconiso o cancellamento da individualidade, antes, procuro evitar este mal, reconhecendo que, na situação economica de nossos dias, a unica maneira de obstar a destruição da individualidade humana, consiste em harmonisal-a com o todo social a que pertence e em não permittir que, desamparada pelo Estado e entregue tão só ás suas forças, venha a perecer na luta.

Como operar, porém, semelhante harmonisação? Substituindo ao falso principio da "autonomia da vontade individual", o principio novo da "solidariedade humana", ou seja, reconhecendo como principios informadores do Direito Publico e Privado a liberdade, a igualdade juridica e a solidariedade, como meio, este ultimo, de concertar, a bem do equilibrio social, as desigualdades de facto que os dois primeiros principios, por si sós, não conseguiram remediar.

Colin e Capitant, expondo os principios fundamentaes do Codigo Civil francez, ainda dizem: "de ha muito, novos conceitos engrandeceram, entre os quaes um, que tende a adquirir uma importancia cada vez maior: o da "solidariedade. $O$ individuo só desenvolve integralmente as suas faculdades pessoaes graças ao concurso, muitas vezes despercebido, mas sempre indispensavel, da communidade a que pertence e com a qual contracta, por isso, uma obrigação, isto é, a de consentir, em sendo preciso, aos sacrificios necessarios para que o Estado possa exercer identica funcção em favor dos outros individuos". 
Assim entendido, o principio de solidariedade é o limite da liberdade e da igualdade, obrigando cada qual aos sacrificios necessarios para o bem da communhão de que faz parte e de cujos proveitos participa.

Nesse sentido, já havia escripto D'Aguanno: "este novo principio modifica o conceito da liberdade, que passa a ser concebida segundo o criterio da maior harmonia com o todo ethico; modifica, outrosim, o conceito da igualdade, que passa a ser entendido como sendo o tratamento desigual dos desiguaes, e modifica, por fim, a idéa das relações entre o Direito Publico e o Direito Privado, destruindo todo o pretendido criterio do antagonismo entre estes dois ramos do direito, por fórma a permittir que as leis de ordem publica se harmonisem com as de ordem privada, para completar a personalidade individual".

\section{A ACÇÃO SOCIAL DO ESTADO}

Para a applicação, pois, de taes principios fundamentaes, de mistér se faz reconhecer ao Estado a faculdade de intervir na esphera do Direito privado - e tal intervenção não ha, hoje, quem legitimamente a conteste.

Não a contestava em 1891 o genial e Santo Padre LEÃo XIII aio fazer, em sua famosa encyclica sobre a questão social (De Rerum Novarum) estas categoricas affirmações: "se, pois, os interesses geraes, ou os interesses de uma classe em particular, apparecem lesados, ou simplesmente ameaçados, e impossivel fôr remediar ou obviar por outra fórma, então é preciso, com indeclinavel necessidade, recorrerse á autoridade publica. Que o Estado se transforme, assim sendo, a um titulo todo particular, na providencia dos trabalhadores, pertencentes á classe pobre, em geral".

Não o contesta, tão pouco, S. S. Pio XI ao dizer, referindo-se á citada encyclica, textualmente o seguinte: quanto á autoridade civil, LEÃo XIII, ultrapassando com audacia os confins impostos pelo liberalismo, ensina, imperterrito, 
que ella não deve limitar-se a tutelar os direitos e a ordem publica, mas antes fazer o possivel "para que as leis e as instituições sejam taes que da propria organisação do Estado dimane espontaneamente a prosperidade da nação e dos individuos". Aos governantes compete defender toda a nação e os membros que a constituem, tendo sempre cuidado especial dos fracos e desherdados da fortuna ao proteger os direitos dos particulares, "porquanto, a classe abastada, munida dos seus proprios recursos, carece menos do auxilio publico; pelo contrario, a classe indigente, desprovida de meios pessoaes, esteia-se sobretudo na protecção do Estado".

Tanto é dizer-se, pois, que as doutrinas mais conservadoras acolheram os novos rumos ditados pelas condições do meio economico-social, preconisando uma correspondente adaptação das instituições politicas.

Dess'arte, duas conclusões, em synthese, eu vos apresento: - primeira, a de que o conceito do "individualismo", não só não é substancial e inherente ao da "Democracia", mas, pelo contrario, deste, por natureza, se afasta; - segunda, a de que, na Democracia pura, a acção social do Estado ha de desenvolver-se parallelamente á acção juridica.

\section{SUCCEDANEOS DA DEMOCRACIA}

Succedaneos da Democracia correm mundo, apesar de tudo, sob rotulos de soluções originaes.

Desprezada a diversidade das etiquetas, o que nelles se apura, em ultima analyse, é a proclamação - não a demonstração! - da fallencia da Democracia e, a seguir, o elogio da dictadura.

Fraca, fraquissima novidade! Esquecem tão tardios apostolos que, na phrase de Assis Brasil, “o despotismo é tâo antigo como o primeiro desvario humano".

Porque, dictadura de direita e dictadura de esquerda são uma coisa só: - despotismo. $\mathrm{E}$ bons ou maus, todos os despotas são despotas. 
Quero ser franco: novidade por novidade, eu ainda ficaria com a do "governo apolitico", que, pelo menos, é disparate genuinamente indigena.

O corporativismo fascista e o syndicalismo communista, estes, não me seduzem sob aspecto algum, pois em ambos vejo a mesma, mesmissima machina em acção: o syndicalismo de Estado. No que differem é na direcção que á manivela o dictador imprime: Mussolini, toca-a da esquerda para a direita e produz, em alta escala, burguezes apatacados; Stalin, move-a da direita para a esquerda e fabrica agitadores para uso interno e externo.

Diz-se que num como noutro regimen a dictadura não é a de um homem, mas, alli, a da propria nação, aqui, a do proletariado. Puro engano! O poder absoluto e discricionario é e sempre foi pessoal por sua' propria essencia. Mas, quando não fosse, pouco se nos daria, porque de individuos, ou de classe, a dictadura sempre é igualmente repellente e ao invés de manter, desfaz, quebra, violenta a harmonia social.

Admitto, sem duvida, o syndicalismo, mas como orgam de classe e não como orgam do Estado, menos ainda como o proprio Estado; admitto e reclamo a acção social do Estado, mas condemno o socialismo de Estado, o Estado unico e supremo tutor dos individuos.

Pede meças a um e outro systema o chamado "governo de technicos", como se a missão do governo fosse, unica e exclusivamente, a de conduzir os interesses materiaes das collectividades, missão, aliás, que mesmo assim concebida, os technicos, por si sós, jamais lograriam realisar, por lhes faltar o nexo politico capaz de uniformisar sua acção.

"Governo de technicos", como se a nação fosse apenas uma officina, ou, segundo alguem disse, "uma sociedade anonyma da qual são accionistas os cidadãos"!

Infelizmente, senhores, essas manipulações politicas, oriundas de laboratorios suspeitos, alguma coisa conseguiram entre nós: a crença, em certos espiritos, de ser pre- 
ciso prolongar a dictadura para reajustar a economia e a vida publica do paiz.

\section{A CONSTITUCIONALISAÇÃO DO PAIZ}

Não chego a comprehender, em boa fé, os autores e doutores desse novo credo.

Por que receiar o restabelecimento da ordem legal?

Não é elle o unico meio para a mais segura reorganisação do paiz?

E' possivel reorganisar fóra do regimen da lei?

Na minha ingenuidade, eu penso, com Plinio Barreto, que o momento politico brasileiro assim se define: "ou a Constituição, ou a anarchia. Ou a Constituição, ou o desmembramento. Ou a Constituição, ou a epidemia do caudilhismo. Ou a Constituição ou a ruina economica".

Não ha mais discutir esta these. Só os que não querem vêr, não vêem o perigo que corremos. Só os que não querem ouvir, não ouvem os anseios da opinião publica.

Mais um esforço, mais uma arrancada, senhores, e a partida está ganha. E' a causa da patria que está em jogo e a victoria está em vossas mãos, meus jovens amigos, dependendo só e só de se coordenar o movimento de opinião já existente, já generalisado de norte a sul do Brasil.

Mais um esforço, mais uma arrancada, uma só, esta de propaganda, de civismo, para que possamos em breve renascer através da

\section{MELHOR DEMOCRACIA}

Muito de vós depende a nova estructura politica do paiz, através da diffusão destes magnos principios:

o governo do povo pelo povo, mediante a eleição livre, consciente e real de seus representantes;

a funcção legal dos partidos, por via do voto proporcional, e, pois, a educação das massas eleitoraes mediante 
a prégação de programmas e não de virtudes pessoaes dos candidatos, e, pois, ainda, a representação, em sentido proprio, como funç̧ão de élites;

a attribuição do processo de reconhecimento eleitoral ao Poder Judiciario;

o respeito á divisão dos poderes, como limite do poder pelo poder;

a adopção fiel de nossos tradicionaes principios federativos e de descentralisação, cuja base é a autonomia municipal;

a mais fervente oração a Deus para que nos livre da tutela a que nos pretende submetter o recente Codigo dos Interventores, presenteando-nos com uma menoridade politica da qual de ha muito sahimos;

a coragem bastante para criar territorios federaes, ao invés de Estados, alli onde a capacidade de emancipação administrativa não se verificou;

a responsabilidade effectiva dos administradores e a presença dos ministros nas casas do Legislativo;

a manutenção do Senado da Republica como Camara Federal por excellencia, na qual os Estados por igual numero de representantes compareçam, contrabalançando as diversidades numericas da Camara dos Deputados, formada por tantos membros quantos resultarem de um coefficiente minimo de população;

a organisação technica da administração, para nos livrar do papelorio e do funccionalismo emperrador e excessivo, adoptando-se os modernos processos de racionalisação do trabalho nos serviços publicos; e, por fim,

a maior amplitude da acção social do Estado, mediante o reconhecimento dos direitos da sociedade, ao par da declaração dos direitos individuaes, realisando-se, assim, os tres principios informadores do Direito: a liberdade, a igualdade perante a lei e a solidariedade humana - tudo, porém, moldado nos justos limites das condições ditadas pelo meioambiente brasileiro, sem importação de modelos feitos para outras collectividades, sem transplantações exóticas. 
Eis, meus amigos, porque discordei de vosso orador: vós não tendes apenas a força, tendes tambem a bandeira. que sabereis seguir com ardor, com energia, com fé nos destinos do Brasil.

Tendes a força. Tendes a directriz. E' dizer: - vosso é o futuro.

Podeis partir tranquillos, sob as bençams de Deus e a saudade de vossos mestres, pois, continuando a trilhar, lá fóra, o caminho aqui iniciado, sereis os pioneiros dessa grande causa nacional e o orgulho desta Faculdade!

DR. VICENTE RÄO

Professor cathedratico de Direito Civil. 